\title{
Da especificidade da filosofia ao seu ensino
}

Antonio Edmilson Paschoal ${ }^{3}$

\section{Resumo}

Este artigo reúne algumas considerações sobre a primeira das "habilidades e competências" esperadas de um formando de filosofia no Brasil, segundo as "Diretrizes curriculares para os cursos de Filosofia", a saber, a "capacitação para um modo especificamente filosófico de formular e propor soluções a problemas, nos diversos campos do conhecimento". O objetivo é demarcar significados da expressão "modo especificamente filosófico" que permitam iniciar uma reflexão sobre metodologias do ensino de filosofia. A hipótese que norteia este trabalho é que na filosofia existe uma imbricação necessária entre conteúdo e método, e não apenas porque nela o conteúdo é o método em movimento, mas porque ela mesma pode ser entendida como um método, na medida justamente em que se configura como um modo específico de apresentar problemas e soluções.

Palavras-chave: filosofia; ensino da filosofia; metodologia do ensino da filosofia.

\section{From the specificity of the Philosophy to her teaching}

\begin{abstract}
This article presents some considerations about the first of the "skills and competencies" expected of a student of philosophy in Brazil, according to the "Curriculum guidelines for courses in Philosophy", namely, the "capacity for a way specifically philosophical to formulate and propose solutions to problems in different fields of knowledge". The goal is to demarcate meanings of the term "specifically philosophical mode" that permits to begin a discussion of methodologies aimed at his production and transmission. The hypothesis that guides this works that there is necessary an overlap between content and method, and not just because the content in the philosophy is the method in movement, but because she herself can be understood as a method, as precisely as she configures itself as a specific mode of presenting problems and solutions.
\end{abstract}

Keywords: philosophy; teacher of philosophy; methodology of teaching philosophy.

${ }^{3}$ Doutor em Filosofia (UNICAMP). Professor do Programa de Pós-Graduação em Filosofia da PUCPR, pesquisador do CNPq. E mail: antonio.paschoal@yahoo.com.br 
A filosofia é a ciência objetiva da verdade, é a ciência da sua necessidade: é o conhecer por conceitos, não é opinar nem deduzir uma opinião da outra. (...) quem tiver estudado e compreendido uma filosofia, contanto que seja filosofia, por isso mesmo, compreendeu a filosofia.

G. W. FR. Hegel ${ }^{4}$

\section{Considerações iniciais}

Se a pergunta o que é a física ou o que é a matemática não é um problema físico ou matemático e tampouco um tema a ser considerado na formulação dos conteúdos e metodologias das disciplinas de física e de matemática, no caso da filosofia ela é central para a sua elaboração como disciplina. De fato, a resposta, ou tentativa de resposta à questão " $o$ que é a filosofia?" não apenas é um dos conteúdos a serem abordados na disciplina de filosofia, como fornece os parâmetros para o estabelecimento de uma metodologia de trabalho com ela. Balizando-a tanto do ponto de vista da compreensão daquele modo próprio de apreender o mundo, quanto no que diz respeito à transmissão desse modo, o que se faz observando-se os diferentes contornos que ele assumiu na história ${ }^{5}$, ou seja, do legado que produziu.

Central, portanto, nos debates sobre o tema da sua produção e transmissão, a questão "o que é a filosofia?" reaparece a cada vez que se tematiza o ensino da filosofia, como se pode verificar nas "Diretrizes curriculares para os cursos de graduação em filosofia" tomadas aqui como ponto de partida para esta reflexão. Nesse documento a "especificidade" da filosofia é colocada em relevo como a primeira das "habilidades e competências" esperadas de um profissional da educação formado num curso de filosofia no Brasil, a "capacitação [do formando] para um modo especificamente filosófico de formular e propor soluções a problemas, nos diversos campos do conhecimento". Nesse documento, porém, visto tratar-se de uma diretriz e não de um debate filosófico, não se encontra uma definição para aquele modo peculiar de formular questões e soluções.

Com outros contornos, essa questão aparece também em um documento ulterior da área, nas Orientações curriculares nacionais para o ensino de filosofia no ensino médio. Dessa vez, além da pergunta pela especificidade da filosofia, são apontadas também algumas pistas para a solução do problema. Primeiro, o documento chama a atenção para caráter polissêmico do termo "filosofia", tendo em vista a pluralidade de respostas que a pergunta "o que é a

\section{${ }^{4}$ HEGEL, 1989, p 98 e 99.}

${ }^{5}$ Em última instância, do ponto de vista de quem aprende a filosofia, aprende-se a filosofar justamente observando o modo como os filósofos construíram seus argumentos e arquitetaram seus edifícios filosóficos. (PASCHOAL, 2008).

${ }^{6}$ Parecer do CNE/CES 492/2001. Documento formulado pelos professores Oswaldo Giacoia Junior, Álvaro Valls e Nelson Gomes. 
filosofia" já recebeu, além de chamar a atenção para o fato de que as respostas aparentemente universais situam-se em campos particulares, precisando ser compreendidas no contexto das tramas que conferem sentido a elas. Segundo, ele reitera a ideia de que, diferentemente do que se verifica em outras ciências, a pergunta pelo "o que é a filosofia" (p. 21) é uma pergunta filosófica, donde se segue que respondê-la já é uma forma de filosofar. Terceiro, postula que é possível, mesmo considerando a ambiguidade das respostas à pergunta o que é a filosofia, demarcar ainda que provisoriamente, a sua peculiaridade, o que pode ser feito observando-se "alguns procedimentos característicos do filosofar" (p. 22). Nesse sentido, destaca, por exemplo, o "sopesar conceitos, solicitar considerandos, mesmo diante de lugarescomuns que aceitaríamos sem reflexão (por exemplo, o mundo existe?) ou de questões bem mais intrincadas, como a que opõe o determinismo de nossas ações ao livre arbítrio” (p. 22).

Tendo como ponto de partida essas pistas, que parecem ressaltar a relação entre os procedimentos do filosofar e a questão do conhecimento, é possível caracterizar a filosofia, provisoriamente, como a arte de quebrar a naturalidade com que normalmente são utilizadas as palavras e os conceitos. Um modo de reflexão que não se restringe aos objetos do conhecimento, mas busca compreender o próprio ato de conhecer. Porquanto, ela seria uma ciência que não se limita à indagação por verdades particulares, mas por inquirir sobre os prérequisitos do modo humano de conhecer e também sobre os critérios, as condições do conhecimento e, acima de tudo, sobre os jogos de poder que permitem a determinadas proposições gozarem do privilégio de serem reconhecidas como verdadeiras em determinados momentos.

Se, contudo, essas considerações iniciais permitem delinear alguns contornos da especificidade da filosofia, outros traços sobre ela devem ser considerados ainda para o embasamento de nossa hipótese de trabalho. Isto porque, segundo ela,o reconhecimento do modo específico com que a filosofia apresenta problemas e soluções é um fator imprescindível para a sua compreensão, num sentido amplo, como um método em particular, visto que ela mesma corresponde a um modo específico de formular questões, propor e debater teses.

Para incluir novos traços naquele delineamento da especificidade da filosofia, tomaremos como ponto de partida algumas observações sobre Tales de Mileto, buscando apontar o que fez aquele pensador receber, pela primeira vez na história, a denominação de filósofo. Passaremos, a seguir, da ideia geral de filósofo e de filosofia para o texto filosófico, visto que a filosofia não seria apenas intuição e doxografia, mas também "explicitação e discurso" (GOLDSCHMIDT, 1970, p. 140) e encerramos mostrando como o estudo da filosofia, respeitadas essas premissas metodológicas, é também um modo de se produzir filosofia.

\section{O filósofo Tales de Mileto}


Um dos primeiros a colocar a questão acerca da diferenciação entre a filosofia e as outras ciências tendo Tales de Mileto como referência é Aristóteles. No início da Metafísica, ao apresentar as peculiaridades que distinguem a filosofia em relação às demais ciências, Aristóteles remonta aos primeiros filósofos, nos quais identifica a preocupação, típica da filosofia, com a "causa primeira" (Metafísica, I, 3, 983 24. ARISTÓTELES, 2005, p. 15) ou, em termos análogos, afirma que eles especulam sobre "os princípios primeiros e as causas" (Metafísica, I, 2, 982b 9-10. ARISTÓTELES, 2005, p. 11). Ou seja, a filosofia desde seu movimento inicial, quando coloca em discussão "aquilo de que todos os seres são constituídos e aquilo de que originalmente derivam e aquilo que por último se dissolvem", ela já estaria se ocupando com o seu objeto mais peculiar: "o elemento e princípio dos seres, na medida em que é uma realidade que permanece sempre mesmo na mudança de suas afecções" (Metafísica I, 3, 983b 10-14. ARISTÓTELES, 2005, p. 15). Diferentemente, portanto, das outras ciências, a filosofia buscaria o "porque" (Metafísica I, 1, 981a 29. ARISTÓTELES, 2005 , p. 5) das coisas que estuda e ocupar-se-ia de um objeto de caráter universal e não prático no sentido de responder a necessidades imediatas além de apresentar um caráter universal e não prático de seu objeto. Nesse sentido, ela atenderia diretamente à natureza do homem que "tende ao saber" (Metafísica, I, 1, 980a 18. ARISTÓTELES, 2005, p. 3) respondendo da forma mais elevada ao seu encantamento diante do mundo.

A estratégia de Aristóteles, de recorrer aos pré-socráticos e em especial Tales de Mileto para resposta à pergunta pela especificidade da filosofia, é compartilhada por vários outros filósofos no futuro. Entre eles, retomamos Hegel e Nietzsche, que do interior de suas filosofias destacam outros traços importantes no sentido de referendar o pensador de Mileto como o primeiro filósofo.

Segundo Hegel, a filosofia começa porque através da proposição de Tales "de que a água é o absoluto ou, como dizem os antigos, o princípio" se tem pela primeira vez a “consciência de que o um é a essência, o verdadeiro, o único que é em si e para si” (HEGEL, 1973, p. 15). Tales seria, portanto, o primeiro pensador a se ocupar de um princípio que é universal porque estaria "ao mesmo tempo, em relação com o singular, com a aparição [e] com a existência do mundo" (HEGEL, 1973, p. 15). Tal princípio universal que, segundo o professor de Berlim, permaneceria sempre independentemente da existência singular e passageira, seria, justamente por esse caráter, o objeto peculiar e exclusivo da investigação filosófica. Hegel, contudo, apesar de reconhecer em Tales aquilo que caracteriza o modo próprio da filosofia de compreender o mundo, critica o pensador jônico afirmando que a "falha" de seu pensamento consistiria no fato de "a água também ser uma coisa singular" (HEGEL, 1973, p. 16) e, portanto, ineficaz para expressar a ideia de um princípio universal que, para Hegel, é um principio espiritual.

Por sua vez, em seu curso sobre os filósofos pré-socráticos, sintetizado, em 1873, num pequeno livrinho que manteve inédito, Nietzsche afirma que, de fato, "a filosofia parece começar com uma ideia absurda, com a proposição: a água é a origem e a matriz de todas as 
coisas". (NIETZSCHE, 1973, p. 16). Segundo o jovem professor de filologia clássica da Universidade de Basel, essa ideia merece a nossa atenção por três motivos: "em primeiro lugar, porque essa proposição enuncia algo sobre a origem das coisas; em segundo lugar porque o faz sem imagem e fabulação; e enfim, em terceiro lugar, porque nela, embora apenas em estado de crisália, está contido o pensamento ‘tudo é um"” (NIETZSCHE, 1973, p. 16). Analisando ainda cada um desses três pontos, o professor acrescenta:

A razão citada em primeiro lugar deixa Tales ainda em comunidade com os religiosos e supersticiosos, a segunda o tira dessa sociedade e no-lo (sic) mostra como investigador da natureza, mas, em virtude da terceira, Tales se torna o primeiro filósofo grego (NIETZSCHE, 1973, p. 16).

De fato, a hipótese formulada por Tales com o material precário que dispunha a partir de suas observações da natureza é falsa, especialmente se for considerada do ponto de vista das ciências que temos hoje. Mais ainda, tal hipótese, segundo Nietzsche, empreende uma "monstruosa generalização". Porém, mais importante do que isso tudo seria o fato de a proposição "tudo é um" do pensador jônico exprimir um "postulado metafísico, uma intuição mística" (NIETZSCHE, 1973, p. 16). Os limites de Tales não estariam, portanto, relacionados ao alcance metafísico de sua proposição, mas à linguagem que ele recorre para explicitá-la, visto ter lançado mão de uma "transposição metafórica" em que o objeto de conhecimento é exposto por meio de uma linguagem estranha ele e que se constitui, por fim, num "um meio raquítico" e "totalmente infiel" (NIETZSCHE, 1973, p. 18).

Neste ponto, além de ampliar as pistas tomadas em nossas considerações iniciais, com um desdobramento de nossa questão inicial acerca da especificidade da filosofia que passa a ressaltar a sua vocação para buscar os princípios últimos e os porquês, tem-se também a enunciação de outro aspecto do problema, o da explicitação da filosofia. Uma preocupação que se apresenta, num primeiro momento, a partir do limite imposto àquela intuição inicial pela linguagem e, em seguida, quando se passa a considerar o próprio discurso filosófico como um fenômeno do qual também se pergunta pelas causas primeiras. Tal preocupação, com a construção do discurso filosófico, vale dizer, com o tema do texto filosófico como explicitação e conteúdo da filosofia, algo que ganhará grande importância numa ciência que se configurará numa tradição escrita, é o segundo ponto que merece destaque quando se analisa o modo peculiar da filosofia de formular questões e apresentar soluções a problemas.

\section{A filosofia que se transmite}

Do mesmo modo como a filosofia se pergunta pelas causas últimas do que existe também ao apresentar-se como um discurso ela deve dar conta dos seus motivos últimos e da coerência que faz dela um sistema ordenado e não um caos. Nesse sentido, considerando-se a filosofia como um fenômeno e tomando-a a partir da ótica de sua construção, cabe mencionar 
a metáfora que a associa a um projeto arquitetônico. Uma metáfora que é utilizada, entre outros, por Descartes, na terceira parte das suas Meditações (DESCARTES, 2001, p. 27), por Kant, em especial no capítulo intitulado "A arquitetônica da razão" de sua Crítica da razão Pura (CRP B 860-879 / KANT, 2008, p. 657-669), e por Schopenhauer no prefácio à primeira edição de $O$ mundo como vontade e representação (SCHOPENHAUER, 2005, p. 19). Uma metáfora ressaltada também por Victor Goldschmid tem seu ensaio sobre metodologias voltadas à leitura de sistemas filosóficos. Para o filósofo francês nascido na Alemanha, a filosofia seria "explicitação e discurso" (GOLDSCHMIDT, 1970, p. 140), na medida em que se constrói como um conjunto de teses articuladas por razões e dispostas em um "tempo lógico" a ser identificado e acompanhado pelo leitor de tal modo que ele poderia, por fim, recolocar em movimento aquele sistema como um músico que executa uma partitura.

A proposição de Goldschmidt, independentemente, neste momento, do alcance de um debate sobre tais metodologias, nos interessa por recolocar a questão básica e fundadora do debate filosófico. De que ele tem por pressuposto o reconhecimento das razões últimas da filosofia que se quer avaliar para refutar ou não. Razões que se encontram no texto filosófico e não em alguma experiência vivida pelo autor e inacessível ao leitor. Assim, o exercício da filosofia, passaria a considerar não apenas um modo de ver o mundo, mas também a sua vocação para o debate de ideias, a explicitação dessas ideias em um texto logicamente ordenado e também o leitor em seu encontro com o texto.

Portanto, além de explicitar um modo de ver o mundo, o texto filosófico consiste num exercício argumentativo peculiar que ao modo de uma construção arquitetônica é deixado para a posteridade como modelo daquele modo de formular questões e solucionar problemas como é próprio à filosofia. Esse material se coloca para o seu leitor, em especial para um estudante, ao mesmo tempo como a transcrição de uma tese, sobre o mundo, por exemplo, mas também por seu caráter próprio, como uma argumentação que não só busca razões, mas se fundamenta em razões.

Dessa forma, mover-se pelos meandros de tais textos, decodificá-los e interpretá-los se torna o meio pelo qual se chegaria ao aprendizado daquilo que seria chamado de filosofar. (PASCHOAL, 2008) Motivo pelo qual, é possível concordar com Hegel, (1989) que ao se aprender um filósofo tem-se as condições mínimas indispensáveis para se aprender a filosofar, visto que mais importante do que o conteúdo aprendido é a apreensão daquele modo próprio de olhar para o mundo, de apresentar teses e questionar que permite a um pensador ser chamado de filósofo.

\section{Considerações finais}

Os pontos apresentados até aqui fornecem elementos suficientes para qualificar a hipótese de que na filosofia há uma imbricação necessária entre conteúdo e método, entre um modo de pensar e uma transmissão que não é apenas dos resultados de uma investigação, mas 
de um modo próprio de formular e responder questões. $\mathrm{O}$ que torna a discussão sobre a especificidade da filosofia um aspecto que não ponto pode ser desconsiderado num debate sobre metodologia(s) de trabalho com a filosofia. Em especial em sala de aula, quando aquela concepção mais ampla de metodologia tende a ganhar contornos de procedimentos orientados para o ensino, esse aspecto não pode ser negligenciado, sob pena de se discutir meios de apreensão de conteúdos e não da própria prática do filosofar. Lembrando que o retorno da filosofia ao ensino médio, responde a uma demanda por uma contribuição que não seria dada por outras ciências, vale dizer, o que inclui certamente os conteúdos próprios da filosofia, sua dogmática, mas em especial pela possibilidade de o jovem daquela fase do ensino ter acesso ao seu modo próprio de formular questões, debater e redigir ideias.

Assim, para além de uma compreensão da metodologia como a busca por meios que tornariam a filosofia mais atraente e apetecível em sala de aula, possivelmente convertendo-a no que ela não é, interessa tomá-la, naquele ambiente, como a possibilidade de experimentar, naquele estágio de formação, o modo filosófico de perguntar pelo sentido do mundo, da existência e da escrita. Resultando em procedimentos que levem os alunos a inquirir pelas causas últimas das coisas numa época em que, por exemplo, não basta saber como funciona um sistema econômico, é necessário perguntar pelo por quê? Por que esse e não outro? Outro não seria possível também? Talvez até melhor? Por que essa moral e não outra? Etc.

Especialmente para essa fase de formação do jovem, o modo propriamente filosófico de apresentar questões que se desprende do texto filosófico, não se encerra na leitura do texto de registro filosófico. Antes, pensado como um "método" esse modo especifico de questionar permite a leitura de textos de outros registros, os não filosóficos. Mais ainda, permite a leitura de registros não textuais, como se tem nos exemplos trabalhados por Foucault e denominados por ele de "domínios não discursivos" (FOUCAULT, 1987, p. 186) como é o caso da prisão, da escola, além dos acontecimentos políticos, que são espaços plenos de significados e passivos de serem lidos.

Assim, tendo em vista a filosofia enquanto disciplina, é possível afirmar que é como uma metodologia que ela se torna um fator interessante na formação dos jovens. Tanto como uma metodologia de trabalho que se pratica em sala de aula, nas atividades de leitura e reflexão, quanto fora dela, quando esse modo específico deve se correlacionar não só com os diversos campos do conhecimento, mas também com os diferentes ambientes de autuação dos jovens. Ambientes em que o homem não busca o saber apenas por sua utilidade prática, como diz o filósofo (Metafísica, II, 982b 21-22), mas tendo em vista o saber, ou finalidades como a própria construção de sua individualidade. Ora, nesse sentido, ele necessita da filosofia, vale dizer, daquela lentidão que se traduz em "não reagir de imediato a um estímulo", em ser "capaz de prorrogar a decisão", numa certa lentidão que corresponde, segundo Nietzsche, o

${ }^{7} \mathrm{CI}$, O que falta aos alemães, 6. Analisamos com mais vagar essa proposição num texto intitulado "A arte de ler nuances" (PASCHOAL, 2012), no qual apresento um aprofundamento da questão da metodologia de leitura de textos filosóficos tendo em vista em especial a filosofia de Nietzsche. 
primeiro motivo pelo qual necessitamos de educadores.

Submetido em 01 de abril de 2013. Aprovado para publicação em 25 de julho de 2013.

\section{REFERÊNCIAS}

ARISTÓTELES. Metafísica. Trad. do grego e comentários de Giovanni Reale. Ed. Brasileira de Marcos Macionilo, Marcelo Perinee Maurélio Barbosa. $2^{\text {a }}$ ed. São Paulo: Ed. Loyola, 2005.

Brasil. MEC. Orientações Curriculares Nacionais para o Ensino Médio. PCN do Ensino Médio; $\mathrm{PCN}+$ do Ensino Médio. Disponível em: http://www.ciadaescola.com.br/downloads/procurar.asp?categoria=161 Acessado em 12 de julho de 2007.

Brasil. MEC. Conselho Nacional de Educação. Câmara de Educação Superior. Parecer CNE/CES $n^{\circ}$ 492/2001, aprovado em 3 de abril de 2001. Diretrizes Curriculares Nacionais dos cursos de Filosofia, História, Geografia, Serviço Social, Comunicação Social, Ciências Sociais, Letras, Biblioteconomia, Arquivologia e Museologia. Diário Oficial da União, Brasília, DF, 9 de julho de 2001.

DESCARTES, R. O discurso do método. Trad. Maria Ermantina Galvão. $2^{\mathrm{a}}$ ed., $3^{\mathrm{a}}$ tiragem. São Paulo: Martins Fontes, 2001.

FOUCAULT, M. A arqueologia do saber. Trad. Luiz Felipe Baeta Neves. $3^{\mathrm{a}}$ ed. Rio de Janeiro: Forense Universitária, 1987.

GOLDSCHMIDT, Victor. Tempo histórico e tempo lógico na interpretação dos sistemas filosóficos. In: A religião de Platão, $2^{\text {a }}$ ed. São Paulo: Difusão Europeia do Livro, 1970, p. 139-147.

HEGEL, G. W. FR. Introdução à história da filosofia. Trad. de Orlando Vitorino, Henrique Cláudio de Lima Vaz, Antonio Pinto de Carvalho. $4^{\text {a }}$ ed. São Paulo: Nova Cultural (Col. Os pensadores), 1989, p. 80-158.

HEGEL, G. W. FR. Preleções sobre a História da Filosofia. Trad. Ernildo Stein. In: SOUZA, J. C. de (Org.). São Paulo: Abril Cultural (Col. Os Pensadores), 1973, p. 15-16 
KANT, I. Crítica da razão pura. $6^{\mathrm{a}}$ ed. Trad. de Manuela Pinto dos Santos e Alexandre Fradique Morujão. Lisboa: Fundação CalousteGulbenkian, 2008.

NIETZSCHE, Fr. A filosofia na época trágica dos gregos. Trad. Rubens R. Torres Filho. In: SOUZA, J. C. de (Org.). São Paulo: Abril Cultural (Col. Os Pensadores), 1973, p. 16-18.

NIETZSCHE, Fr. Crepúsculo dos ídolos. Trad. Paulo César de Souza. São Paulo: Companhia das Letras, 2006.

PASCHOAL, A. E. Da utilidade da filosofia para a vida. In: AZEREDO, V. D. Nietzsche - filosofia e educação. Ijuí: Editora Unijuí, 2008, p. 155-168.

PASCHOAL, A. E. A arte de ler nuances. In: AZEREDO, V. D.\& SILVA JR, I. Nietzsche e a interpretação. Curitiba: CRV, São Paulo: Humanitas, 2012, p. 71-80.

SHOPENHAUER, A. O mundo como vontade e como representação. Trad. Jair Barboza. São Paulo: Editora UNESP, 2005. 